\title{
Peran Orang Tua Dalam Pendidikan Moral Anak Katolik Pada Era Pandemi Covid-19 di Kota Malang
}

\author{
Lorentius Goa \\ Sekolah Tinggi Pastoral (STP-IPI) Malang, Indonesia \\ Email : lorensgoa@gmail.com
}

\begin{abstract}
Moral edu cation is one of the important elements in education in the digital era 4.0. without adequate moral education. Children will become victims of advances in information technology that is increasingly fast and sophisticated. This study was conducted to find out, what is the role of parents in children's education during the COVID-19 pandemic? In addition, it was also disclosed whether the parents had carried out this role well or not? This research uses descriptive quantitative method. The method of data collection was done by distributing closed questionnaires to 100 parents who have children who are attending elementary school in Malang City, East Java. Data collection was carried out for three months in early 2021. The moral education referred to in the study includes six indicators; sexuality, solidarity, pluralism, justice, honesty and love for the environment. From the research conducted, it was found that parents in Malang City, East Java have a role in children's moral education. In addition, parents have also played a good role in moral education.
\end{abstract}

Keywords : Covid-19; Education; Moral.

\begin{abstract}
Abstrak. Pendidikan moral menjadi salah satu elemen penting dalam pendidikan di era digital 4.0. tanpa pendidikan moral yang memadai. Anak-anak akan menjadi korban dari kemajuan teknologi informasi yang semakin cepat dan canggih. Penelitian ini dilakukan untuk mengetahui, apa peran orang tua dalam pendidikan anak pada masa pandemi covid-19? Selain itu diungkap juga apakah orang tua sudah menjalankan peran tersebut dengan baik atau tidak? Penelitian ini menggunakan metode kuantitatif deskriptif. Metode pengumpulan data dilakukan dengan menyebar kuesioner tertutup kepada 100 orang tua yang memiliki anakanak yang menempuh pendidikan sekolah dasar di Kota Malang, Jawa Timur. Pengumpulan data dilakukan selama tiga bulan di awal tahun 2021. Pendidikan moral yang dimaksud di dalam penelitian mencakup enam indikator; seksualitas, solidaritas, kemajemukan, keadilan, kejujuran dan cinta lingkungan. Dari penelitian yang dilakukan, ditemukan bahwa orang tua di Kota Malang, Jawa Timur memiliki peran dalam pendidikan moral anak. Selain itu para orang tua juga sudah menjalankan peran dalam pendidikan moral dengan baik.
\end{abstract}

Kata Kunci : Covid-19; Pendidikan; Moral.

\section{PENDAHULUAN}

Pandemi covid-19 yang terjadi di dunia, merubah struktur kesehatan, ekonomi dan sosial, termasuk dunia pendidikan (Yang, 2020). Masyarakat dunia yang terbiasa melakukan kegiatan tatap muka, di berbagai sektor kehidupan kemudian dibatasi, harus melakukan jaga jarak (physical distancing) (Nguyen et al., 2021). Satu sama lain, sesama manusia dilarang untuk saling bersentuhan (Bracis et al., 2021). Kegiatan yang selama ini membuat orang satu dengan yang lain akrab secara fisik, dibatasi (Portegijs et al., 2021). Sejumlah negara menerapkan aturan yang melarang warganya bepergian keluar negeri, dan sebaliknya melarang warga di luar warga negara untuk datang ke negara bersangkutan, seperti yang dilakukan Australia (Beck \& Hensher, 2021). Tak hanya antarnegara, sesama warga negara juga dilarang melakukan aktivitas yang memungkinkan orang bertemu satu sama lain (Mogaji, 2020). Salah satu sektor yang terkena dampak larangan bertemu adalah bidang pendidikan (Jogezai et al., 2021). Sekolah dilarang melakukan kegiatan pembelajaran 
tatap muka (Kirsch et al., 2021). Sekolah dilaksanakan secara daring, melalui fasilitas teknologi informasi atau gadget (Chang et al., 2021).

Di Indonesia, kegiatan pembelajaran juga dilakukan secara daring. Sejak Maret 2020, saat awal pandemi mengguncang Indonesia, kegiatan belajar-mengajar di sekolah ditiadakan, dialihkan sekolah secara daring (Purnama et al., 2021). Indonesia yang secara infrastruktur teknologi informasi belum memadai, mengalami dampak negatif dari kegiatan pembelajaran secara daring, khususnya siswa sekolah dasar dan menengah (Siron et al., 2020). Banyak orang tua, terutama yang berada di pelosok, tidak dapat menyediakan fasilitas bagi anak-anak mereka untuk mengikuti pembelajaran secara daring (Setiawan \& lasha, 2020). Pemerintah juga tidak memberi bantuan fasilitas bagi orang tua yang tidak memiliki perangkat pembelajaran secara daring (R. S. Putri et al., 2020). Hal ini semakin diperparah dengan kondisi di pelosok yang tidak sepenuhnya bisa mengakses jaringan 4G secara baik (E. R. Putri, 2021). Sehingga pada saat anak-anak mengikuti pembelajaran prosesnya juga tidak berjalan maksimal (Fahruni \& Wiryosutomo, 2021).

Hal yang sama juga terjadi di Malang, Jawa Timur. Anak-anak yang sedang bersekolah di tingkat dasar dan menengah mendapati persoalan baru. Di Kota Malang, yang terbilang kota maju, kota pendidikan dan berkembang pesat anak-anak dapat mengikuti pembelajaran secara daring (Ramanta \& Widayanti, 2020). Namun justeru kegiatan pembelajaran secara daring ini yang kemudian menimbulkan persoalan bagi anak-anak di Kota Malang, Jawa Timur. Waktu penggunaan gawai untuk pembelajaran lebih sedikit, bila dibandingkan dengan penggunaan gawai untuk keperluan bermain game, melakukan aktivitas di media sosial dan lain-lain (Wulandari et al., 2021).

Hal ini yang menjadi persoalan dan tantangan bagi orang tua yang berada di Kota Malang. Anak-anak mendapat semacam kebebasan untuk menggunakan gawai yang disediakan oleh orang tua untuk mengikuti pembelajaran secara daring (Sari, 2020). Penggunaan gawai oleh anak di tingkat sekolah dasar dan menengah dalam proses pembelajaran daring lepas dari pengawasan orang tua. Meskipun banyak orang tua yang berupaya untuk mengontrol aktivitas anak-anak mereka di gawai (Farantika \& Indrawati, 2021). Namun tidak semua orang tua yang memiliki kesadaran dan kepedulian terhadap hal tersebut. Orang tua lebih banyak yang abai terhadap aktivitas anak-anak mereka di sosial media melalui gawai yang dipegang (Ummah et al., 2021).

$\mathrm{Hal}$ ini berpengaruh terhadap perilaku dan sikap moral anak-anak di Kota Malang. Anak-anak yang sudah terbiasa dengan berbagai aktivitas di gawai, terpengaruh dengan konten dan sajian dari gawai yang diakses. Penelitian ini dilakukan untuk mengetahui apakah ada peran orang tua di dalam pendidikan moral anak, khususnya anak-anak dengan orang tua yang beragama Katolik di Kota Malang, Jawa Timur? Apakah peran tersebut dijalankan dengan baik?

\section{METODE PENELITIAN}

Metode penelitian ini adalah penelitian kuantitatif. Pengumpulan data dilakukan dengan menyebar kuesioner sebanyak 100 kuis kepada orang tua yang memiliki anak yang sedang menempuh pendidikan sekolah dasar di wilayah Malang, Jawa Timur. Orang tua yang mengisi kuesioner adalah orang tua beragama Katolik. Hal ini dilakukan untuk mengetahui peran orang tua secara khusus, yang beragama Katolik dalam pendidikan moral anak pada masa pandemi covid-19. Malang dipilih karena merupakan salah satu kota di Indonesia yang mendapat julukan kota pendidikan. Malang menjadi tujuan belajar anak-anak dari berbagai wilayah di Indonesia. Tidak hanya pendidikan tinggi, namun juga pendidikan menengah dan dasar. Penyebaran kuesioner dilakukan selama awal tahun 2021, dengan bertemu langsung dengan orang yang mengisi kuis.

Variabel penelitian merupakan variabel tunggal yaitu apakah ada peran orang tua, dengan enam sub variabelnya yaitu seksualitas (I), solidaritas (II), keadilan (III), kejujuran (IV), kemajemukan (V), dan cinta lingkungan (VI), dan apakah peran tersebut sudah dijalankan dengan baik atau tidak. Metode yang digunakan dalam mengambil data penelitian adalah angket tertutup. Analisis data menggunakan rumus scoring untuk memberi skor atau nilai pada kuis atau angket, yang diisi oleh subjek penelitian khususnya menjawab rumusan masalah pertama "apakah ada peran orang tua dalam pendidikan moral anak Katolik di Malang pada masa pandemi covid-19?" Kedua, "apakah 
orang sudah menjalankan perannya dengan baik atau tidak?" Adapun karakteristik penelitian terdiri dari dua hal, yaitu jawaban "ya" diberi skor 2, sedangkan jawaban "tidak" diberi skor 1 . Rumus scoring, sebagai berikut: $\mathrm{S}=\frac{2(A)+1(B)}{N}$, dengan keterangan: $\mathrm{S}=$ Skor yang diperoleh, $2(\mathrm{~A})+1(\mathrm{~B})=$ jumlah dari jawaban responden, dan $\mathrm{N}$ merupakan subjek penelitian.

Rumus lain yang digunakan dalam analisa data penelitian ini adalah rumus binomial, untuk dapat melihat perbedaan peran orang tua yang satu dengan orang tua yang lain dalam pendidikan moral anak. Binomial atau disebut juga distribusi kemungkinan Bernoulli. Distribusi Binomial terdiri dari dua kluster, yaitu kluster berperan dan kluster tidak berperan. Rumus Distribusi Binomial adalah sebagai berikut, $\mathrm{Z}=\frac{(x \pm 0,5)-N P}{\sqrt{N P Q}}$, dengan keterangan, $\mathrm{Z}$ merupakan nilai Binomial, $\mathrm{x}$ adalah banyaknya kasus yang muncul, $\mathrm{N}$ keseluruhan kasus yang diobservasi, $\mathrm{P}$ merupakan proporsi kasus yang diharapkan terdapat dalam satu kategori, dan $\mathrm{Q}$ adalah proporsi kasus yang diharapkan terdapat dalam kategori lainnya.

\section{HASIL PENELITIAN DAN PEMBAHASAN}

Peneliti menyajikan hasil penelitian menggunakan rumus scoring dan rumus binomial secara keseluruhan dari enam bidang penelitian untuk memperoleh skor rata-rata dalam bentuk tabel.

Tabel 1. Penyajian data scoring secara keseluruhan (Sumber: Peneliti, 2021).

\begin{tabular}{|c|c|c|c|}
\hline \multirow{3}{*}{ Bidang } & & & $N=100$ \\
\hline & \multirow{2}{*}{ No Item } & \multicolumn{2}{|c|}{ Scoring } \\
\hline & & A & B \\
\hline I & $1-5$ & 8 & 1 \\
\hline II & $6-13$ & 14,2 & 0,9 \\
\hline II & $14-16$ & 5,2 & 0,4 \\
\hline IV & $17-20$ & 7,6 & 0,2 \\
\hline V & $21-23$ & 5,93 & 00.03 \\
\hline VI & $24-25$ & 3,6 & 0,2 \\
\hline \multirow{3}{*}{\multicolumn{2}{|c|}{$\begin{array}{c}\text { Jumlah } \\
\text { Score Rata-rata }\end{array}$}} & 44,53 & 2,70 \\
\hline & & \multicolumn{2}{|c|}{47,23} \\
\hline & & \multicolumn{2}{|c|}{1,88} \\
\hline
\end{tabular}

Penyajian data secara keseluruhan menggunakan rumus Binomial terhadap enam bidang penelitian untuk menjawab rumusan masalah kedua, perbedaan peran orang tua yang satu dengan lainnya dalam pendidikan moral anak.

Tabel 2. Penyajian data binomial secara keseluruhan (Sumber: Peneliti, 2021).

\begin{tabular}{|c|c|c|c|c|c|c|}
\hline & & & & & & $\mathrm{N}=100$ \\
\hline No & No & Binom & & & & Total \\
\hline Bidang & Item & $A$ & Z & B & Z & \\
\hline I & $1-5$ & 24 & 3,1 & 6 & $-3,1$ & 30 \\
\hline II & $6-13$ & 26,63 & 4,06 & 3,38 & $-4,06$ & 30,01 \\
\hline III & $14-16$ & 26 & 3,83 & 4 & $-3,83$ & 30 \\
\hline IV & $17-20$ & 28,5 & 4,7 & 1,5 & $-4,7$ & 30 \\
\hline V & $21-23$ & 29,67 & 5,17 & 0,33 & $-5,17$ & 30 \\
\hline VI & $24-25$ & 27 & 4,2 & 3 & $-4,2$ & 30 \\
\hline Jumlah & & 161,8 & 25,1 & 18,2 & $-25,1$ & 180,01 \\
\hline Rata-Ra & & 26,97 & 4,18 & 3,04 & $-4,18$ & 30,002 \\
\hline
\end{tabular}


Berdasarkan skor rata-rata yang diperoleh seperti pada tabel 2, peneliti membahasnya berdasarkan enam bidang penelitian.

Pertama, seksualitas. Dari 100 responden dalam lima item yang disajikan pada bidang seksualitas, diperoleh nilai rata-rata 1,8, artinya dalam hal pendidikan seksualitas peran orang tua sudah baik. Sedangkan hasil pengolahan data statistik binomial diperoleh nilai Z:3,1 jika dibandingkan dengan nilai tabel, maka nilai $Z$ tersebut $<0,008$ dari taraf signifikan 0,05 . Dengan demikian, dalam pendidikan seksualitas orang tua sudah berperan.

Kedua, solidaritas. Dengan menggunakan rumus scoring diperoleh nilai rata-rata 1,89 , artinya dalam pendidikan solidaritas, peran orang tua sudah baik. Dari hasil pengolahan data tes statistik binomial diperoleh nilai z: 4,06 jika dibandingkan dengan nilai tabel, maka nilai z tersebut $<0,0003$ dari taraf signifikan 0,05. Artinya dalam pendidikan solidaritas orang tua sudah berperan.

Ketiga, keadilan. Dari 100 responden dan tiga item yang disajikan dengan menggunakan rumus scoring diperoleh nilai rata-rata 1,87 , artinya dalam hal pendidikan keadilan orang tua sudah baik. Sedangkan tes statistik binomial diperoleh nilai z: 3,83 jika dibandingkan dengan nilai tabel, maka nilai $z$ tersebut $<0,0007$ dari taraf signifikan 0,05 . Hal ini berarti dalam pendidikan moral keadilan, orang tua sudah berperan.

Keempat, kejujuran. Dengan menggunakan rumus scoring diperoleh nilai rata-rata 1,95, yang berarti dalam pendidikan moral khususnya kejujuran, peran orang tua sudah baik. Tes statistik binomial diperoleh nilai z: 4,75, jika dibandingkan dengan nilai tabel, maka nilai z tersebut $<0,0003$ dari taraf signifikan 0,05. Dengan demikian, dalam pendidikan kejujuran, orang tua sudah berperan.

Kelima, kemajemukan. Dari 100 responden dan tiga item yang disajikan pada bidang kemajemukan, dengan menggunakan rumus scoring diperoleh nilai rata-rata 1,99, artinya dalam hal pendidikan kemajemukan peran orang tua sudah baik. Dari hasil pengolahan data tes statistik binomial diperoleh nilai z: 5,17, jika dibandingkan dengan nilai tabel, maka nilai z tersebut $<0,0003$ dari taraf signifikan 0,05. Dalam hal kemajemukan, orang tua sudah berperan.

Keenam, cinta kepada lingkungan. Dari 100 responden dan dua item yang disajikan pada bidang cinta kepada lingkungan, dengan menggunakan rumus scoring diperoleh nilai rata-rata 1,9. Artinya dalam hal pendidikan cinta kepada lingkungan, peran orang tua sudah baik. Dari hasil pengolahan data tes statistik binomial diperoleh nilai z: 4,2 jika dibandingkan dengan nilai tabel, maka nilai $z$ tersebut $<0,0003$ dari taraf signifikan 0,05 . Dengan demikian, dalam hal pendidikan moral, cinta kepada lingkungan orang tua sudah berperan.

Orang tua memiliki peran besar terhadap pendidikan anak. orang tua dapat mengembangkan seluruh aspek pribadi anak. Ada banyak perang peran orang tua dalam pendidikan anak. Pertama, orang tua sebagai guru pertama dan utama bagi anak. Orang tua mengajarkan anaknya tentang kehidupan. Pada masa awal anak-anak, orang tua memiliki otoritas penuh untuk memberikan stimulasi. Apa pun yang diterima anak dari orang tuanya baik yang didengar, dilihat, dan dirasakan merupakan pendidikan yang diterima anak dan selanjutnya diterapkan dalam kehidupan sehari-hari. Kedua, orang tua adalah pelindung utama bagi anak. Anak berhak untuk mendapatkan perlindungan dari orang dewasa dan orang tua yang paling bertanggung jawab terhadap perlindungan anak. Kondisi fisik dan mental anak masih lemah dan tidak mampu melawan otoritas orang dewasa. Anak membutuhkan orang tua yang melindungi dan memberi rasa aman. Ketiga, orang tua sebagai sumber kehidupan bagi anak. Kehidupan anak tidak bisa dipisahkan dari dari orang tua. Kehidupan anak menjadi tanggung jawab orang tua ketika anak belum sampai pada tingkat kemandirian. Keempat, orang tua sebagai tempat bergantung bagi anak, baik secara fisik maupun mental. Ketika dalam kandungan, anak bergantung pada ibunya melalui plasenta. Ketika anak sudah lahir anak juga masih bergantung kepada orang tua sampai orang tua mempunyai kehidupan sendiri. Kelima, orang tua merupakan sumber kebahagiaan bagi anak. Memberikan kasih sayang kepada anak adalah bagian yang paling utama bagi anak karena kasih sayang orang tua merupakan bagian kebahagiaan bagi anak (Derung, 2019).

Setelah anak-anak sudah memasuki usia sekolah dasar, peran orang tua masih tetap dibutuhkan, tidak hanya peran dalam pengasuhan, namun juga peran dalam pendidikan moral. 
Pendidikan moral menjadi bagian penting dalam pendidikan anak-anak. Sebab anak-anak sudah memasuki fase dimana ia perlu diperkenalkan dan diberi pengetahuan mengenai baik buruk dan benar salah. Pendidikan moral anak pada usia sekolah dasar lebih menitikberatkan pada faktor psikomotorik anak. Anak lebih banyak meniru dari apa yang dilakukan orang tuanya. Sehingga orang tua perlu memberi contoh yang baik dalam hal moral kepada anak-anak. Orang tua yang sedang mendidik anak, perlu menampilkan sikap moral yang baik di depan anak-anak (Khaironi, 2017).

Anak-anak pada usia sekolah dasar sedang berada pada level meniru (mengimitasi) orangorang yang ada di sekitarnya. Orang yang paling dekat dan paling sering berinteraksi dengan anakanak adalah orang tua. Pada usia anak-anak pada masa pertumbuhan seperti itu berlaku teori tabularasa yang dikemukakan oleh Francis Bacon. Dalam teori tabularasa, anak-anak yang lahir seperti kertas putih yang masih kosong belum ditulis apa-apa. Orang-orang sekitar yang kemudian mengisi tulisan di kertas kosong tersebut (Rekret, 2018).

Sementara itu menurut Emile Durkheim, untuk menjadi anak yang bermoral perlu adanya kedisiplinan, keterikatan terhadap kelompok dan otonomi dalam menentukan sikap. Sehingga, tidak hanya diberi contoh, anak-anak perlu diberi kebebasan untuk mengekpresikan apa yang telah dilihat dan dikonsumsinya. Orang tua perlu memberi kebebasan kepada anak, selama apa yang dilakukan anak tidak membahayakan nyawanya dan tidak melanggar moral yang telah diajarkan (Sinulingga, 2016). Memberi kebebasan kepada anak akan melahirkan dan menumbuhkan sikap yang mandiri pada anak dalam menjalankan aktivitas sehari-hari. Sikap mandiri merupakan bagian penting dari anak-anak yang sedang tumbuh dan berkembang (Fadlan \& Kasmadi, 2019). Anak-anak yang mandiri dapat bertahan pada berbagai situasi dan kondisi yang dihadapi. Tak sekadar mampu bertahan, namun juga mampu membantu orang lain untuk berdaya (Hidayaturrahman \& Husamah, 2021).

Pendidikan moral berarti upaya untuk membawa seseorang untuk hidup dan berperilaku dengan baik. Dalam keluarga Katolik pendidikan moral adalah sekolah nilai-nilai kemanusiaan dan iman Katolik. Anak perlu dibimbing agar bertumbuh menjadi pribadi yang baik dengan cara-cara yang sesuai dengan tahap perkembangan kepribadiannya (Moa, 2013). Setidaknya ada enam unsur penting dalam pendidikan moral Katolik yang dibahas di dalam penelitian; pendidikan seksualitas, solidaritas, keadilan, kejujuran, kemajemukan, cinta kepada lingkungan.

Pertama, seksualitas. Seksualitas merupakan proses seseorang mengalami, menghayati, dan mengekspresikan diri sebagai makhluk seksual. Seksualitas berarti seseorang yang berpikir, merasa dan bertindak berdasarkan posisinya sebagai makhluk seksual (Lidiawati et al., 2020). Seksualitas diekspresikan melalui interaksi dengan individu dari jenis kelamin yang berbeda dan mencakup pikiran, pengalaman, pelajaran, ideal, nilai, fantasi, dan emosi. Seksualitas berhubungan dengan proses seseorang merasa tentang diri mereka dan bagaimana mereka mengkomunikasikan perasaan tersebut kepada lawan jenis melalui tindakan yang dilakukan. Seperti sentuhan, ciuman, pelukan, dan melalui perilaku yang lebih halus, seperti isyarat gerakan tubuh, berpakaian, dan perbendaharaan kata (Lutfi \& Suryati, 2019).

Pendidikan seksualitas sangat penting bagi anak agar anak tumbuh menjadi generasi muda yang berkualitas. Banyak kasus pergaulan bebas yang muncul dewasa ini (Ashaari et al., 2019). Pergaulan bebas dipicu oleh semakin berkembangnya ilmu pengetahuan dan teknologi. Salah satu perkembangan yang amat modern adalah media sosial, berupa handphone android yang selalu menyajikan fitur-fitur yang amat canggih dari waktu ke waktu untuk kelancaran pemenuhan hidup manusia (Savitri et al., 2019). Selain untuk pemenuhan hidup, fitur-fitur yang ada dalam media sosial ini juga menyediakan hal-hal yang bersifat negatif, seperti gambar dan video porno, gambar dan video kekerasan, dan masih banyak fitur lain yang mengajarkan hal negatif yang dapat membentuk karakter negatif pula untuk anak (Shofiyah, 2020).

Peran orang tua sangat penting untuk mendampingi dan memberikan informasi seputar seksualitas sejak dini. Pendidikan seksualitas dimulai dari keluarga inti, keluarga besar, dan lingkungan sekitar. Maka dari itu orang tua sebaiknya bertanggung jawab dalam memberikan pendidikan seksualitas pada anak. Peran orang tua dalam pendidikan seksualitas anak, meliputi; 
mengenal anggota tubuh, mengenal gender, bergaul dengan orang lain di luar keluarga inti, menjadi teman yang baik, dan mengenal identitas diri (Yafie, 2017).

Kedua, solidaritas. Bila dikaitkan dengan kelompok sosial, solidaritas merupakan rasa kebersamaan dalam suatu kelompok tertentu yang menyangkut tentang kesetiakawanan dalam mencapai tujuan dan keinginan yang sama. Solidaritas sosial mengacu kepada pendapat Emile Durkheim merupakan kohesi yang ada antara anggota suatu asosiasi, kelompok, kelas sosial, kasta, dan antara berbagai individu dan kelompok, maupun kelas-kelas membentuk masyarakat, dengan bagian-bagiannya (Saidang \& Suparman, 2019). Orang tua menjadi tempat pertama untuk mengembangkan aspek sosial anak, sehingga anak memperoleh bekal yang memungkinkan untuk menjadi anggota masyarakat yang berguna kelak. Peran orang tua dalam membangun solidaritas adalah menghormati orang yang sedang beribadah. Mengajarkan kepada anak saling memberi dan tolong menolong kepada sesama (Tanjung et al., 2020). Orang tua memperkenalkan kepada anak bagaimana berempati pada orang lain, agar anak lebih peka terhadap lingkungan sekitar, sehingga timbullah rasa peduli, empati dengan cara merasakan apa yang orang lain rasakan (Rifai, 2019). Bersama keluarga, kebiasaan berbagi juga bisa ditanamkan saat anak diajarkan untuk tidak egois dan mudah memberi. Orang tua bisa mulai saat momen saat makan bersama dengan meminta anak mengambil makanan sambil mengatakan 'minta tolong'. Nilai solidaritas lainnya adalah menghormati orang yang lebih tua, mengucapkan selamat kepada orang yang merayakan hari raya, mengajarkan kepada anak agar tidak memilih-milih teman, menghargai orang yang tidak sesuku, berbeda kepercayaan dan status, mengajak anaknya untuk terlibat adil dalam keluarga dengan kegiatan kerja bakti, memberikan salam kepada orang tua ketika hendak bepergian (Zaluchu, 2017).

Ketiga, keadilan. Keadilan merupakan suatu bentuk keseimbangan yang ada dalam kehidupan. Keadilan menurut Thomas Aquinas merupakan landasan dalam kehidupan, yang mengarahkan manusia dalam membangun relasi dengan sesama manusia (Arum, 2019). Peran Orang tua dalam menerapkan keadilan dalam keluarga, harus secara sadar dan disengaja agar nilai keadilan dapat tumbuh dalam kehidupan keluarganya. Peran orang tua dalam menerapkan keadilan sebagai berikut; berperilaku adil kepada anak sesuai dengan kebutuhan masing-masing anak. Cinta tanpa syarat juga menjadi nilai yang sangat penting dalam pendidikan moral anak. Orang tua berusaha mencintai semua anak tanpa syarat (Diana, 2019). Berperilaku dan bertutur kata jujur dan apa adanya menjadi hal yang penting dalam keluarga.

Keempat, kejujuran. Pendidikan kejujuran merupakan bagian penting dari tanggung jawab dan peran orang tua. Dari orang tua anak-anak pertama kali belajar kejujuran dan kebohongan. Anak yang tahu orang tuanya sering berbohong cenderung meniru sikap orang tua tersebut. Sebaliknya anak yang suka melihat orang tuanya yang jujur, maka anak akan meniru perbuatan tersebut. Penanaman sikap jujur bagi anak memang tidak semata-mata pada faktor kognisinya, namun lebih penting pada faktor afektif dan psikomotorik (Rochmawati, 2018). Bahwa anak sudah tahu kalau berbohong itu salah dan dosa, mencuri dan korupsi juga perbuatan dosa. Yang paling penting bagi orang tua adalah menunjukkan sikap dan perbuatan jujur yang konsisten kepada anak-anak. Sekali anak tahu orang tuanya tidak jujur, anak tidak akan mudah untuk dibuat percaya. Dan itu berbahaya bagi masa depan anak-anak. Anak juga akan mudah berbohong kepada temannya, kepada gurunya, termasuk kepada orang tuanya sendiri (Cleopatra et al., 2020).

Kelima, kemajemukan. Setiap orang yang lahir ke dunia berbeda, tidak ada yang sama. Bahkan bayi yang lahir kembar sekalipun memiliki banyak perbedaan. Artinya orang hidup memiliki perbedaan dan keragaman. Keragaman merupakan khazanah dan kekayaan yang bisa saling melengkapi (Tanggur \& Nitte, 2019). Orang tua memiliki peran untuk mendidik dan mengajar anaknya mengenai nilai moral kemajemukan. Sehingga dalam kehidupan sehari-hari, anak akan menghargai setiap perbedaan, tidak mudah menyalahkan, tidak merasa benar sendiri. Dan memiliki perhatian terhadap teman yang berbeda. Bahkan anak-anak sudah memiliki sikap yang menghormati perbedaan di antara diri dan temannya (Sugiharto, 2020). Dalam ajaran Katolik, kemajemukan juga akan melahirkan sikap kasih dan sayang anak kepada mereka yang berbeda dalam hal apapun (Noti \& Darmawan, 2016). 
Keenam, cinta kepada lingkungan. Pendidikan moral yang baik adalah mencintai lingkungan. Mencintai lingkungan dengan tidak mengotori, apalagi merusaknya. Mencintai lingkungan berarti menjaga dan merawatnya (Apriati et al., 2021). Orang tua perlu membanguna kesadaran kepada anak-anak bahwa bencana yang terjadi di dunia, seperti banjir, longsor, rob air, dan lain-lain disebabkan oleh perusakan lingkungan. Anak-anak sejak dini perlu diberi pendidikan untuk cinta terhadap lingkungan alam. Bisa dengan pendidikan yang bersifat kognitif, bisa pula dengan afektif dan psikomotorik (Mansur \& Bare, 2019). Anak-anak diajak jalan ke tempat wisata alam yang indah. Sebaliknya anak perlu juga dibawa ke lokasi bencana untuk berbagi dengan korban, dan melihat langsung lokasi kerusakan yang diakibatkan oleh manusia yang tidak mencintai, atau malah merusak lingkungan (Adriansyah et al., 2016).

Pada masa pandemic covid-19 orang tua memiliki tantangan tersendiri di dalam pendidikan moral anak-anak mereka, tak terkecuali bagi orang tua yang beragama Katolik. Peran orang tua pada masa pandemi ini cukup kompleks. Tidak hanya harus menjadi role model bagi anak-anak, tapi juga menjadi super mom dan super daddy (Kurniati et al., 2020). Harus bisa mengerjakan pekerjaan dan tugas-tugas yang selama ini tidak dikerjakan. Seperti mengajarkan anak mata pelajaran di sekolah. Hal ini terjadi karena waktu pembelajaran secara daring sangat terbatas dan banyak hambatan serta gangguan. Selain itu, juga menjaga anak supaya tidak berinteraksi dengan orang di luar yang kemungkinan menjadi potensi transmisi covid-19. Konsekuensi, orang tua harus menjadi teman bermain yang intens bagi anak-anak. Hal tersebut harus dilakukan orang tua sambil bekerja untuk mencari nafkah, demi menghidupi diri dan keluarga, termasuk anak-anak.

Orang tua pada masa pandemic covid-19 juga memili peran sebagai pemberi contoh motivasi yang baik bagi anak-anak. Selain memberi contoh, dengan segala kemampuan yang dimiliki orang tua, harus mampu memberi dukungan dan motivator terhadap anak yang sering merasa bosan selama berhari-hari atau bahkan berbulan-bulan berada di rumah (Iftitah \& Anawaty, 2020). Peran yang berat bagi orang tua tentunya. Selama ini anak memiliki banyak teman yang bisa menjadi teman berbagi cerita dan kisah, terutama saat berada di sekolah. Kini orang tua mengambil peran tersebut.

Meski berat, para orang tua tetap bisa menjalankan perannya dalam pendidikan anak-anak, termasuk dalam pendidikan moral. Sebagaimana yang diperankan oleh orang tua yang beragama Katolik di Kota Malang, Jawa Timur. Peran tersebut sudah dijalankan secara baik dan memadai. Para orang tua butuh adaptasi dan pembiasaan dalam menghadapi situasi yang berubah cepat dan tentu saja di luar prediksi berbagai kalangan. Peran orang tua dituntut lebih dinamis pada masa pandemi covid-19. Orang tua yang berada di kota besar, dan kota pendidikan seperti Malang, Jawa Timur.

Salah satu kelemahan dan kekurangan penelitian ini adalah, belum mengukur sejauhmana peran orang tua dalam pendidikan moral Katolik yang berada di wilayah pedesaan dan pelosok. Pelitian lanjutan kiranya dilakukan oleh peneliti lain, sehingga dapat diketahui dengan baik, bagaimana peran orang tua dalam pendidikan moral Katolik bagi anak-anak di wilayah pedesaan dan pelosok pada masa pandemi covid-19.

\section{KESIMPULAN}

Peran orang tua dalam pendidikan moral anak Katolik di Malang, Jawa Timur pada masa pandemi covid-19, memperoleh skor 1,88. Artinya dalam pelaksanaan pendidikan moral anak Katolik, orang tua menjalankan perannya dengan baik. Berdasarkan hasil pengolahan data menggunakan uji binomial tentang peran orang tua dalam pendidikan moral anak Katolik di Malang, Jawa Timur pada masa pandemi covid-19, diperoleh nilai $z=4,18$. Jika dibandingkan dengan nilai tabel, maka nilai tersebut $<0,0003$ dari taraf signifikan 0,05 . Jadi dalam hal ini ada peran orang tua yang yang sangat besar dalam pendidikan moral anak Katolik di Malang, Jawa Timur pada masa pandemi covid-19. 


\section{DAFTAR PUSTAKA}

Adriansyah, M. A., Sofia, L., \& Rifayanti, R. (2016). Pengaruh Pelatihan Pendidikan Lingkungan Hidup Terhadap Sikap Peduli Anak Akan Kelestarian Lingkungan. Psikostudia: Jurnal Psikologi, 5(2), 86-106. https://doi.org/10.30872/psikostudia.v5i2.2281

Apriati, Y., Azkia, L., \& Alfisyah, A. (2021). Upaya Meningkatkan Kepedulian Siswa MIN 5 Barito Kuala Terhadap Lingkungan Hidup Melalui Edukasi Lingkungan. Bubungan Tinggi: Jurnal Pengabdian Masyarakat, 3(2), 152. https://doi.org/10.20527/btjpm.v3i2.3381

Arum, G. A. (2019). Konsep Keadilan (lustitia) Perspektif St. Thomas Aquinas Dan Relevansinya Bagi Pemaknaan Sila V Pancasila. Lumen Veritatis: Jurnal Filsafat Dan Teologi, 10(1), 23-44. https://doi.org/10.30822/lumenveritatis.v10i1.207

Ashaari, N. N. S. B. H., Sumadi, S. N. B., Salleh, N. A. B., Nlsmail, aziera I. B., Adenan, N. A. H. B., \& Husin, M. R. Bin. (2019). Masalah Pergaulan Bebas dalam Kalangan Remaja Sekolah. International Journal of Humanities, Management and Social Science, 2(1), 38-50. https://doi.org/10.36079/lamintang.ij-humass-0201.21

Beck, M. J., \& Hensher, D. A. (2021). Australia 6 months after COVID-19 restrictions- part 1: Changes to travel activity and attitude to measures. Transport Policy, June. https://doi.org/10.1016/j.tranpol.2021.06.006

Bracis, C., Burns, E., Moore, M., Swan, D., Reeves, D. B., Schiffer, J. T., \& Dimitrov, D. (2021). Widespread testing, case isolation and contact tracing may allow safe school reopening with continued moderate physical distancing: A modeling analysis of King County, WA data. Infectious Disease Modelling, 6, 24-35. https://doi.org/10.1016/j.idm.2020.11.003

Chang, T.-Y., Hsu, M.-L., Kwon, J.-S., Kusdhany, M. L. S., \& Hong, G. (2021). Effect of online learning for dental education in asia during the pandemic of COVID-19. Journal of Dental Sciences, $x x x x$. https://doi.org/10.1016/j.jds.2021.06.006

Cleopatra, M., Sahrazad, S., \& Wulansari, L. (2020). Peran Orang Tua dan Guru dalam Mencegah Berita "Hoax" Pada Siswa SMP. Jurnal Ilmiah Wahana Pendidikan, 6(3), 100-103. https://doi.org/https://doi.org/10.5281/zenodo.3737983

Derung, T. (2019). Pastoral Yang Mengembangkan Persaudaraan Insani Ditinjau Dari Sosiologis. 4859.

Diana, R. (2019). Prinsip Teologi Kristen Pendidikan Orang tua terhadap Anak di Era Revolusi Industri 4.0. BIA': Jurnal Teologi Dan Pendidikan Kristen Kontekstual, 2(1), 27-39. https://doi.org/10.34307/b.v2i1.79

Fadlan, A., \& Kasmadi, N. (2019). Pola Asuh Orang Tua Dalam Pembinaan Moral Anak Usia Dini. SMART KIDS: Jurnal Pendidikan Islam Anak Usia Dini, 1(2), 37. https://doi.org/10.30631/smartkids.v1i2.55

Fahruni, E. F., \& Wiryosutomo, H. W. (2021). Analisis Faktor-Faktor Penyebab Perilaku Malas Belajar Daring Saat Pandemi COVID-19 Pada Siswa Kelas XII SMA Negeri 1 Menganti Gresik. Jurnal BK UNESA, 12(2), 22-36. https://jurnalmahasiswa.unesa.ac.id/index.php/jurnal-bkunesa/article/view/36431

Farantika, D., \& Indrawati, D. (2021). Sistem Pembelajaran Dari Rumah Melalui Model Daring TK Al Muhajirin Kota Malang Saat Pandemi Covid-19. Jurnal Pendidikan: Riset Dan Konseptual, 5(1), 128. https://doi.org/10.28926/riset_konseptual.v5i1.326

Hidayaturrahman, M., \& Husamah, H. (2021). Participation in building human resources: Independent strategies for facing a demographic expansion in a remote island. In Ashadi, J. Priyana, \& Basikin (Eds.), Teacher Education and Professional Development in Industry 4.0 (pp. 141-150). CRC Press. https://doi.org/10.1201/9781003035978-22

Iftitah, S. L., \& Anawaty, M. F. (2020). Peran Orang Tua Dalam Mendampingi Anak Di Rumah Selama Pandemi Covid-19. JCE (Journal of Childhood Education), 4(2), 71-81. https://doi.org/10.30736/jce.v4i2.256

Jogezai, N. A., Baloch, F. A., Jaffar, M., Shah, T., Khilji, G. K., \& Bashir, S. (2021). Teachers' attitudes towards social media (SM) use in online learning amid the COVID-19 pandemic: the effects of 
SM use by teachers and religious scholars during physical distancing. Heliyon, 7(4), e06781. https://doi.org/10.1016/j.heliyon.2021.e06781

Khaironi, M. (2017). Pendidikan Moral Pada Anak Usia Dini. Jurnal Golden Age, 1(01), 1. https://doi.org/10.29408/goldenage.v1i01.479

Kirsch, C., Engel de Abreu, P. M. J., Neumann, S., \& Wealer, C. (2021). Practices and experiences of distant education during the COVID-19 pandemic: The perspectives of six- to sixteen-year-olds from three high-income countries. International Journal of Educational Research Open, 22(April), 100049. https://doi.org/10.1016/j.ijedro.2021.100049

Kurniati, E., Alfaeni, N. D. K., \& Andriani, F. (2020). Analisis Peran Orang Tua dalam Mendampingi Anak di Masa Pandemi Covid-19. Jurnal Obsesi: Jurnal Pendidikan Anak Usia Dini, 5(1), 241. https://doi.org/10.31004/obsesi.v5i1.541

Lidiawati, K. R., Simanjuntak, E. J., \& Dewi, W. P. (2020). Psikoedukasi Pendidikan Seksualitas: "Love, Sex And Dating" Pada Remaja. Prosiding Konferensi Nasional Pengabdian Kepada Masyarakat Dan Corporate Social Responsibility (PKM-CSR), 3, 440-445. https://doi.org/10.37695/pkmcsr.v3i0.1004

Lutfi, L., \& Suryati, S. (2019). Pendidikan Kesehatan Meningkatkan Pengetahuan Remaja Tentang Seksualitas. Jurnal Keperawatan Respati Yogyakarta, 6(3). https://doi.org/10.35842/jkry.v6i3.394

Mansur, \& Bare, Y. (2019). Meningkatkan Hasil Belajar Siswa pada Konsep Perubahan dan Pelestarian Lingkungan Hidup dengan Model Discovery Learning di SMAS Katolik ST Gabriel Maumere. BIOEDUSCIENCE: Jurnal Pendidikan Biologi Dan Sains, 3(2), 84-89. https://doi.org/10.29405/j.bes/3284-893298

Moa, A. (2013). Tugas perutusan keluarga kristen dalam pendidikan moral anak menurut amanat apostolik familiaris consortio. Logos, Jurnal Filsafat-Teologi, 10(2), 31-50. http://www.ejournal.ust.ac.id/index.php/LOGOS/article/view/877

Mogaji, E. (2020). Impact of COVID-19 on transportation in Lagos, Nigeria. Transportation Research Interdisciplinary Perspectives, 6, 100154. https://doi.org/10.1016/j.trip.2020.100154

Nguyen, M. H., Hargittai, E., \& Marler, W. (2021). Digital inequality in communication during a time of physical distancing: The case of COVID-19. Computers in Human Behavior, 120, 106717. https://doi.org/10.1016/j.chb.2021.106717

Noti, F. B., \& Darmawan, I. P. A. (2016). Identitas kristen dan peran pendidikan agama kristen di tengah kemajemukan. Prosiding Seminar Nasional Pendidikan Agama Kristen, April, 68-73. https://semnas.sttsimpson.ac.id/index.php/SNPK/article/view/9

Portegijs, E., Keskinen, K. E., Tuomola, E. M., Hinrichs, T., Saajanaho, M., \& Rantanen, T. (2021). Older adults' activity destinations before and during COVID-19 restrictions: From a variety of activities to mostly physical exercise close to home. Health and Place, 68, 102533. https://doi.org/10.1016/j.healthplace.2021.102533

Purnama, S., Ulfah, M., Machali, I., Wibowo, A., \& Narmaditya, B. S. (2021). Does Digital Literacy Influence Students' Online Risk? Evidence from Covid-19. Heliyon, 7(June), e07406. https://doi.org/10.1016/j.heliyon.2021.e07406

Putri, E. R. (2021). EFL teachers' challenges for online learning in rural areas. Teflin Nasional Seminar, 402-409. http://utns.proceedings.id/index.php/utns/article/view/133/119

Putri, R. S., Purwanto, A., Pramono, R., Asbari, M., Wijayanti, L. M., \& Hyun, C. C. (2020). Impact of the COVID-19 pandemic on online home learning: An explorative study of primary schools in Indonesia. International Journal of Advanced Science and Technology, 29(5), 4809-4818. http://sersc.org/journals/index.php/IJAST/article/view/13867/7119

Ramanta, D., \& Widayanti, F. D. (2020). Pembelajaran Daring di Sekolah Menengah Kejuruan Putra Indonesia Malang pada Masa Pandemi COVID-19. Prosiding Seminar Bimbingan Dan Konseling, O(0), 61-67. http://conference.um.ac.id/index.php/bk2/article/view/81

Rekret, P. (2018). The posthumanist tabula rasa. Research in Education, 101(1), 25-29. https://doi.org/10.1177/0034523718792162 
Rifai, R. (2019). Upaya Meningkatkan Sikap Solidaritas dan Hasil Belajar dengan Menggunakan Media Grafis "Monas Mama." DUNAMIS: Jurnal Teologi Dan Pendidikan Kristiani, 3(2), 212-222. https://doi.org/10.30648/dun.v3i2.196

Rochmawati, N. (2018). Peran Guru dan Orang Tua Membentuk Karakter Jujur Pada Anak. Jurnal AlFikri: Jurnal Studi Dan Penelitian Pendidikan Islam, 1(2), 1-12. https://doi.org/http://dx.doi.org/10.30659/jspi.v1i2.3203

Saidang, S., \& Suparman, S. (2019). Pola Pembentukan Solidaritas Sosial dalam Kelompok Sosial Antara Pelajar. Edumaspul: Jurnal Pendidikan, 3(2), 122-126. https://doi.org/10.33487/edumaspul.v3i2.140

Sari, T. T. (2020). Self-Efficacy dan Dukungan Keluarga Dalam Keberhasilan Belajar Dari Rumah di Masa Pandemi Covid-19. Education Journal : Journal Educational Research and Development, 4(2), 127-136. https://doi.org/10.31537/ej.v4i2.346

Savitri, G. A., Kholis, N., \& Zunaidah, A. (2019). Pola Interaksi Orang Tua dan Anak di Perkotaan Dalam Menghadapi Dampak Negatif Penggunaan Gadget. JURNAL SOSIAL : Jurnal Penelitian IImu-IImu Sosial, 20(1), 15-20. https://doi.org/10.33319/sos.v20i1.17

Setiawan, B., \& lasha, V. (2020). Covid-19 Pandemic: the Influence of Full-Online Learning for Elementary School in Rural Areas. Jurnal Pendidikan Sekolah Dasar, 6(2), 114-123. https://doi.org/http://dx.doi.org/10.30870/jpsd.v6i2.8400.g5942

Shofiyah. (2020). Dampak Media Sosial dan Pornografi Terhadap Perilaku Seks Bebas Anak di Bawah Umur. Alamtara: Jurnal Komunikasi Dan Penyiaran Islam, 4(1), 57-68. https://ejournal.iaitabah.ac.id/index.php/alamtaraok/article/download/503/373/

Sinulingga, S. P. (2016). Teori Pendidikan Moral Menurut Emile Durkheim Relevansinya Bagi Pendidikan Moral Anak Di Indonesia. Jurnal Filsafat, 26(2), 214. https://doi.org/10.22146/jf.12784

Siron, Y., Wibowo, A., \& Narmaditya, B. S. (2020). Factors Affecting the Adoption of E-Learning in Indonesia: Lesson From Covid-19. Journal of Technology and Science Education, 10(2), 282-295-. https://doi.org/10.3926/jotse.1025

Sugiharto, A. (2020). Keselamatan Eksklusif dalam Yesus di Tengah Kemajemukan Beragama. Angelion Jurnal Teologi Dan Pendidikan Kristen, 1(2), 98-112. https://doi.org/https://doi.org/10.38189/jan.v1i2.66

Tanggur, F. S., \& Nitte, Y. M. (2019). Praktik Pendidikan Agama Pada Siswa-Siswi Non Katolik Di Sekolah Dasar Katolik Se-Kota Kupang. Jurnal Pendidikan Dan Kebudayaan Missio, 11(2), 179316. http://jurnal.unikastpaulus.ac.id/index.php/jpkm/article/view/162

Tanjung, A. W., Ellesia, N., Budiharjo, I. S., \& Hanis, U. (2020). Meningkatkan Rasa Persaudaraan Dan Solidaritas Pertemanan Antar Siswa Untuk Menghindari Bullying. Dedikasi Pkm, 1(1), 111. https://doi.org/10.32493/dedikasipkm.v1i1.6064

Ummah, S., Mansur, R., \& Setiawan, E. (2021). Storytelling melalui daring terhadap kemampuan kognitif anak usia dini di kelompok bermain $(\mathrm{kb})$ nanda ceria bocek karangploso kabupaten malang. Dewantara, 3(1), 20-34. http://riset.unisma.ac.id/index.php/fai/index

Wulandari, S. P., Umayaroh, S., \& Mahanani, P. (2021). Analisis Dampak Negatif Penggunaan Smartphone pada Pembelajaran Daring Ditinjau dari Perilaku Anak Kelas V SD. Jurnal Pembelajaran, Bimbingan, Dan Pengelolaan Pendidikan, 1(6), 456-464. https://doi.org/10.17977/um065v1i62021p456-464

Yafie, E. (2017). Pendidikan seksual anak usia dini. Jurnal CARE (Children Advisory Research and EducationResearch and Education), 4(2), 18-30. http://ejournal.unipma.ac.id/index.php/JPAUD/article/view/956

Yang, J. (2020). Major Power Relations in a Post-Pandemic World Order. China Quarterly of International Strategic Studies, 6(1), 1-18. https://doi.org/10.1142/S2377740020500074

Zaluchu, S. (2017). Penderitaan Kristus Sebagai Wujud Solidaritas Allah Kepada Manusia. DUNAMIS: Jurnal Penelitian Teologi Dan Pendidikan Kristiani, 2(1), 61-74. https://doi.org/10.30648/dun.v2i1.129 